\title{
Ammi majus an Endemic Medicinal Plant: A Review of the Medicinal Uses, Pharmacological and Phytochemicals
}

\author{
Mohammad Amzad Hossain ${ }^{1 *}$ and S Al Touby ${ }^{2}$ \\ ${ }^{1}$ School of Pharmacy, College of Pharmacy and Nursing, University of Nizwa, Nizwa, Sultanate of Oman, Oman \\ ${ }^{2}$ School of Nursing, College of Pharmacy and Nursing, University of Nizwa, Nizwa, Sultanate of Oman, Oman
}

\begin{abstract}
Recently, most of the rural areas people are using alternative medicine for the treatment of diseases because they believe that natural medicine is always safe and economical. In the Gulf region, the Ammi majus (A. majus) is used traditionally as a safe and sustainable herbal medicine to treat various chronic ulcers. A. majus extracts showed significant biological activity such as antiviral, antimicrobial, antioxidant, relaxant effect, cardiovascular effect, hypotensive etc. The synonyms of $A$. majus belong to this family showed the equivalent biological activity. The selected $A$. majus species and its few synonyms including wild species are available in the Southern part of Oman. The literature search showed that only few in vitro biological investigations were done on the selected species that is available in Oman. The plant extracts and its individual phytochemicals showed potential activity against different biological activity. More than fifty bioactive phytochemicals were isolated from the particular plant species but the main groups of phytochemicals that are potential against different biological activities are flavonoids and coumarins. However, in Oman, there are many basic research parameters related to biological activities such as essential oils, animal study and clinic studies are unidentified on the selected plant species. In addition, the isolation and characterization of biologically active phytochemicals particularly the major phytochemicals flavonoids and coumarins are also unidentified. In conclusion, this current review is to summarize the biological and phytochemical status of the selected Omani species that is currently used traditionally by the local ethnic communities to treat different chronic ulcers.
\end{abstract}

\section{Keywords}

Ammi majus, Apiaceae, Review, Phytochemical status, Biological status, Oman

\section{Introduction}

\section{Plant description}

Coumarins and flavonoids are both secondary metabolic heterocyclic organic phytochemicals, which are very important phytochemicals for the formulation of drugs due to their medicinal values. Recently, the literature showed that both the phytochemicals have been extensively used as synthetic antioxidants to foodstuffs. However, the use of synthetic antioxidants has arisen to be questioned because of their significant poisonousness $[1,2]$. There is some extensive curiosity in protective medicine and in food manufacturing in the expansion of natural antioxidants found from plant sources, especially herbal plants [3]. Most of the plant species detected as medicinal plants have been used to treat human diseases for centuries as medications or prevention of ailments because the plant species contain significant active phytochemicals such as flavonoids, coumarins, alkaloids, terpenoids, amino acid, essential oil with therapeutic value [4-6]. Therefore, day by day significantly increasing use of plant extracts and formulated remedies in the diet, cosmetic and drug industries recommends that, in order to find bioactive phytochemicals in the crude extracts, a systematic study of medicinal plants is very important $[2,5]$. Therefore, the focus of this current review is to summarize the present biological and phytochemicals status of the selected indigenous plant species, which is currently used traditionally by the local ethnic communities to treat different chronic ulcers. Also, the aim is to review the biopharmaceutical effects of both secondary metabolic heterocyclic organic phytochemicals in humans and the mechanism of action that contribute to the biological activities.

Ammi majus (A. majus) is a wild medicinal plant, which belongs to the Apiaceae family. The selected plant species was

*Corresponding author: Dr. Mohammad Amzad Hossain, Associate Professor, School of Pharmacy, College of Pharmacy and Nursing, University of Nizwa, Sultanate of Oman, Oman, Tel: +96899708496

Accepted: October 13, 2020

Published online: October 15, 2020

Citation: Hossain MA, Al Touby S (2020) Ammi majus an Endemic Medicinal Plant: A Review of the Medicinal Uses, Pharmacological and Phytochemicals. Ann Toxicol 2(1):9-14 

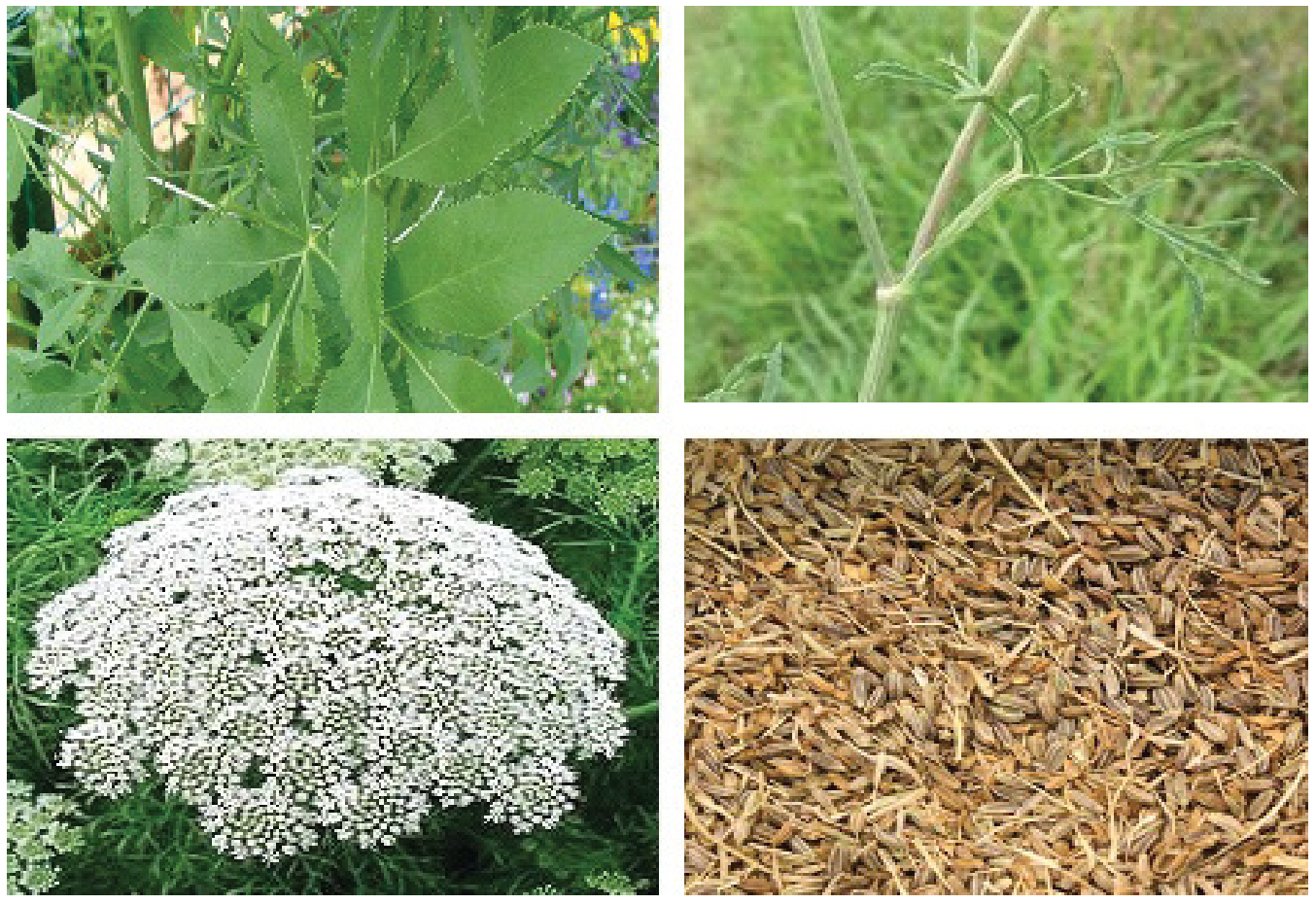

Figure 1: Plant picture of Ammi majus.

initially invented from Egypt. After that the selected plant is widely spread in Europe, Mediterranean and Western Asia, Argentina, Chile, Mexico and other European countries. However, the selected plant is first cultivated in Indian region and other tropical countries since the old time due to its traditional uses $[7,8]$. The main traditional uses of the selected plant worldwide were to regulate menstruation and diuretic [7-9]. Not only that, the plant is used to treat a wide range of human diseases such as leprosy, kidney stones and infections $[7,8,10]$. The plant is also found Arabian countries included in the Southern part of Oman. The scientific name is Ammi majus L. But its common name is Bishop's weed, Queen Anne's lace, Ammee. The plant has several Arabic names in the Arabian countries: Khella Shaytani, Aziza, Zind Al-Aroos, Khalat Barr, Khizaran, Khella Kubra. The environment/weather of the particular mentioned areas is more appropriate to cultivate the selected plant species. The plant is an annual herb with straight branches. It achieves a height of up to 1-2.0 meter (Figure 1). The root is similar to carrot fattened. Generally, the leaves are egg-shaped and occasionally triangular in shape. The length of the leaves is approximately $20 \mathrm{~cm}$ with numerous branches alternately arranged. The stems are also numerous branches. The flowers are normally in white colour swollen from the base. The woody hard parts of the flowers are used as toothpicks. The shape of flowers are symmetrical pentamerous and tetracyclic $[7,8,11]$. The fruit is approximately 2-3 $\mathrm{mm}$ in length with fully egg-shaped (Figure 1). Most species and synonyms belong to this family are flowering and seeds producing plants and normally it contains two seeds in the seed coat.

\section{Synonyms}

The selected plant species first invents from Egypt and currently it is spread throughout Europe, Western Asia, Middle East and other subtropical countries including the Southern part of Oman [12-14]. About 300 to 455 genera and more than 3000 to 3750 species are recognized belongs to this family and most of them including the selected plant species are small flowering plants. Most of the species and their synonyms are economically important vegetables such as carrot, parsnip, celery, coriander, anise, caraway, cumin, parsley, dill etc. In addition, the isolated essential oils from them are also very important for their medicinal and economic point of view. The selected particular plant species have about twenty-two synonyms and most of them are existing worldwide. But, the literature showed that only nine synonyms are available in the Arabian countries including Oman. The most common synonyms are as follows: Aethusa ammi Spreng; A. boeberi Hell; A. broussonetii DC; A. cicutifolium; A. elatum Salisb; A. glaucifolium L; A. intermedium DC; $A$. pauciradiatum Hochst; $A$. pumilum (Brot.) DC; $A$. pinnatum; A. ammi; A. ammi-maius; $A$. candollei; $A$. petraeum; A. pumilum; Carum majus; Cuminum aethiopicum; Cuminum regium; Daucus glaber; Daucus parsae; Selinum ammoides; Sison pumilum Brot.

\section{Taxonomy}

Kingdom: Plantae; Subkingdom: Vascular plants; Superdivision: Seed plants; Division: Flowering plants; Class: Dicotyledons; Subclass: Rosidae; Order: Apiales; Family: Apiaceae; Genus: Ammi L.; Species: Ammi majus L.

\section{Distribution}

The plant is considered as fields of winter crops in the Nile Delta and Valley, also in the Oases and the Mediterranean region. It is also distributed in North Africa, Middle East, and Europe. The plant species grows as a wildflower in the fields 
of winter crop cornflakes like wheat and barley. Currently, the selected plant is widely distributed in most of the European countries, India and the tropical countries. The particular plant species is cultured in India and other tropical countries due to its significant biological activity and traditional uses $[7,8]$. The particular plant is a flowering and seeds producing plant $[7,8,11]$ which first originates from Egypt. Later on, the particular plant is spread all over the subtropical countries. It is widely distributed in certain specific places or areas namely Europe, Mediterranean and western Asia, Argentina, Chile and Mexico [7-9]. The plant is approximately 1 to 1.5 meters tall. In Oman, the selected plant is widely available in the Southern part of Oman. Even though the plant is existing in the other part of Oman. Because of the atmosphere of the Southern part of Oman it is more appropriate to grow the selected plant. It is a yearly herb with conventional branches starting from the ground (Figure 1). More than nine species are found in the Sultanate of Oman. Most of the species are found at AL-Jabal Al-Akhdar, Northern Oman, AL-Hamra and Salalah [15]. Therefore, the Omanis are planning to promote commercially of the selected plant species in the near future.

\section{Medicinal uses}

The particular plant species and other species belongs to this family are used traditionally as folk medicine worldwide to treat several human diseases. The selected particular plant species has potential medicinal action against different incurable human diseases. The paste of aerial parts is used to treat skin problems, psoriasis and vitiligo. The ripen fruits as powder or water extract are used to regularize menstruation problems, leprosy, kidney and gallbladder stones, and other several infections. The same is also used as a carminative to treat angina pectoris. Egyptians are using the organic fruits extract traditionally to treat hypertension, depression, leucoderma, allergic rhinitis and rash [16-21]. The water extract of ripen fruits is used to treat coronary and chronic asthma $[22,23]$. The water and hydro alcoholic extracts of the particular plant species showed significant diaphoretic, carminative, antispasmodic and antiseptic activates [16-18]. Therefore, both extracts (water and hydro alcoholic) were used as herbal medicines to treat different ailments since the old time. The plant water extracts were used by the Omanis to treat ulcer, skin (leukoderma), and regularize menstruation [13,14]. Till now, only few studies related to biological activities have been conducted on the selected plant species grown in Oman by our group. Therefore, this present review work is based on evaluating the biological and phytochemical status of the locally grown plant species.

\section{Plant extracts}

Several methods such as Soxhlet and maceration methods were reported for the preparation of extracts from the selected plant species. Most of the authors were reported maceration method for the preparation of plant extract by using direct solvent [17]. However, previously, our group was reported different process of extraction by using methanol and then successively partitioned by various solvents with polarity ascending pattern [13]. Though, the preparation of extraction process is different but the extractive values almost similar.
The prepared extracts were used to evaluate their in-vitro and in-vivo phytochemical, biological and toxicological studies which were reported by several authors $[13,14,17]$.

\section{Phytochemical status}

According to the previous phytochemical reports showed that the particular plant contains substantial numbers of different acyclic and cyclic or aromatic and heterocyclic compounds. The main group of phytochemicals such as pyrones, saponins, flavonoids, coumarins and essential oils which were reported by several authors $[17,24,25]$. However, most of the authors are specifying the main phytochemicals of the selected plant species are furanochromone and coumarins derivatives includes khellin, visnadine, ammoidin, visnagin, visammiol, samidin, xanthotoxin, and khellinin $[13,14]$. But none of them isolated the phytochemicals from the selected plant species which was grown in Oman. Recently, one report showed that about eleven polyphenols compounds along with monoglycosides, aglycones, triglycoside and diglycosides are isolated from the selected plant species [26-28]. Most of the reported isolated individuals have shown significant pharmacological activity which can be used as markers to treat human diseases. More recently, the researchers including our group are working hard to isolate some biologically active phytochemical from the selected plant species including Omani species which can actively participate in the biological activities. Some preliminary work regards to in vitro biological activities were done on the selected plant species by our group. However, so far our best knowledge nobody works on the isolation of phytochemicals, essential oil and their in vivo studies on the selected plant species grown in Oman.

\section{Pharmacological Activities}

A. majus is considered as a wild vegetable plant which is used traditionally to treat different ailments. The roots, leaves, stems, fruits and their paste of the selected plant are equally used traditionally to treat particular diseases $[21,29]$. Since ancient times, scientists are working continuously on the various parts of the selected plant species related to phytochemicals and pharmacological activities for medicinal uses [30]. Based on pharmacological activities, the researchers are working continuously on different parts as well as the different polarities of extracts of the selected plant and isolated and characterized some pharmacologically active phytochemicals which can be used as remedy to treat diseases [30]. Eventually, not a single report was found on the isolation and characterization of pharmacologically active phytochemicals of the selected plant species which is grown in Oman. Therefore, our group is trying to work on that selected plant species to isolate the bioactive phytochemicals that can be used to treat different diseases.

\section{Antidiabetic activity}

The various polarities plant extracts and individual phytochemicals were used to determine their antioxidant activity by different established in vitro methods as well as in vivo animal models $[29,31]$. Previously, almost all reports exhibited that different extracts of this family's plant showed diverse antidiabetic activity. Majority of their results exhibit- 
ed that the highest antidiabetic activity was obtained in the plant extracts with maximum polarity. That means the highest polarity extract contains most of the antidiabetic activity guided phytochemicals. Hence, the overall conclusion is that the antidiabetic activity was directly linked to the polarity of the plant extracts $[32,33]$. Regrettably, we are unable to determine and compare the antidiabetic activity of the locally grown selected plant species due to the shortage of lab resources and herbs.

\section{Antioxidant activity}

All polarity plant extracts were determined by their antioxidant activity by different in vitro and in vivo models [13$15,17,30]$. The previous antioxidant activity results related to the particular plant species showed that all prepared extracts exhibited significant antioxidant activity against various conventional models. Among them, majority results declared that high antioxidant activity was found from the most polar extract e.g., methanol extract. Though, our previous results on the same species done by our group displayed that the high activity was found in the nonpolar extracts e.g., hexane as well as chloroform extracts [34]. That means our results completely differ from their antioxidant results reported by others $[15,17]$. The variation of antioxidant results of various extracts may be due to the phytochemicals, sample harvesting, sample processing, rainfall, sunlight and extraction procedures. Our previous extraction procedure was that the powder samples extracted directly with methanol and it was then fractionated by the diverse polarity of solvents. However, their extraction procedure was different from ours, they prepared extract from coarse powder samples by adding solvent directly starting from nonpolar and gradually increased the polarity. Even though the geographical distributions, sample process, drying of plant materials are also not the same like ours.

\section{Antimicrobial activity}

The zone of inhibition of the prepared different plant extracts was determined against different Gram (+ and -) microorganisms by several authors using several established methods including disc diffusion method. All polarities extracts of the particular plant showed remarkable zones of inhibition against different isolated microorganisms. Previous results stated that the aqueous ethyl acetate and chloroform extracts of the selected plant showed the maximum zone of inhibition against the Gram ( + and -) microbes. However, the majority of authors also stated that the maximum zone of inhibition was in the $100 \%$ chloroform extract against different microbes. That means the zones of diameter inhibition are not persistent for the particular prepared plant extracts. But, our inhibition results showed that notable inhibition was found of various extracts against the human isolated microorganisms. The maximum zone of inhibition was obtained by our group in chloroform extract from the indigenous plant species $[26,35]$. Therefore, the chloroform extract could be contained the highest amount of active phytochemicals with a high percentage which is directly involved for the diameter zone of inhibition. Our results vary from other reported values it could be due to the plant harvesting, processing, temperature, and extraction procedures. This variation of inhibition results also depends on types of microbes, incubation time and concentration of the extracts. The remarkable zone of inhibition of the selected plant extract will be used for the separation of phytochemicals.

\section{Cytotoxic activity}

The cytotoxic activity of the selected plant extracts was assessed by well-established in vitro and in vivo methods [35]. Among the extracts, the cytotoxic activity results displayed that the aqueous ethanol extract gives maximum activity on the breast cancer cell line [27]. Their results also showed that chloroform, ethyl acetate and butanol extracts give the prominent cytotoxic activity against the brine shrimp lethally method. Best of our knowledge, nobody investigated the particular plant grown in Oman related to cytotoxicity. Therefore, our group, the College of Pharmacy and Nursing, University of Nizwais planning to do the cytotoxicity of the selected particular plant extracts within a short time.

\section{Antifertility activity}

The antifertility activity of the selected particular plant extracts was assessed by using different in-vivo animal models. Majority previous findings exhibited that methanol extract gives the maximum antifertility activity compared to other prepared plant extracts. The permissible dose of the plant extract accelerate fertility activity but excessive dose it can cause miscarriage. The other extracts of the selected particular plant also give the promising activity against the animal model. However, still, the antifertility activity of the particular plant species grown in Oman is undermined. Therefore, our research group is also planning to conduct the antifertility activity of the selected plant extracts by using the rat model within a short time.

\section{Wound healing activity}

Normally, the wound healing activity of the particular plant extracts was assessed by using in vitro and animal models. The researchers found that the polar extract from the particular plant showed remarkable healing activity. They also stated that the polar extracts of the particular plant contain phytochemicals flavonoids and it could be healed very fast compared to less polarity extracts or phytochemicals. Plenty of work related to healing was done on the particular plant even though on their synonyms. They concluded that all the synonyms of the selected plant have significant activity against the healing. However, nobody works on the healing activity of the synonyms available in Oman including the selected plant by in vitro and animal models.

\section{Total Phenols}

The vast number of previous research was conducted to assess the total phenols content by the common FCR method $[13,14]$. However, the results for total phenols of specific plant extracts are varied in the aerial parts like leaf, roots, and stems. In addition, the phenol results of the particular plant extracts are also varied from polarity to polarity. Majority authors stated that the highest amount of total phenols of the 
particular plant was found from highly polar extract and some of them stated that the high amount is found from the semi polar extract $[36,37]$.

\section{Total Flavonoids}

The total flavonoids content of the particular plant extracts was assessed by using the well-established $\mathrm{AlCl}_{3}$ method $[13,14,17]$. However, the previous reports for total flavonoids of the selected plant showed that the results always vary from plant part to part. It also varies from polarity to polarity of extract. Majority of authors stated that the remarkable amount of total flavonoids found from the semi polar extract and minority authors stated that the remarkable amount is obtained from polar solvent. Our result on the selected Omani species contains the highest amount of total flavonoids in the water extract (most polar solvent).

\section{Conclusion}

The particular plant species including nine synonyms is existing in Oman. Almost all nine synonyms including $A$. majus are also available in the Arabian Gulf. The selected plant has been used traditionally as a folk medicine in the Gulf region for the treatment of chronic ulcers and to regularize menstruation problems. Due to its traditional uses, the selected plant species are cultivated in most tropical countries commercially. A good number of phytochemicals are already isolated from the particular plant species. Some of the isolated phytochemicals showed remarkable pharmacological activities and the extracts of this species also showed different pharmacological activity. The plant extracts and their purified phytochemicals could be used as natural safe medicine to treat different ailments. Our future aim is to determine active extract for the isolation of phytochemicals with potential activity that will be used for the treatment of chronic ulcers and to regularize menstruation problems. Therefore, the aim of this review work is to inspire the young scientists to carry out research on the particular plant species for discovery of new drugs.

\section{Ethical Approval}

Not applicable.

\section{References}

1. Ito N, Fukushina S, Tsuda $\mathrm{H}$ (1985) Carcinogenicity and modification of the carcinogenic response by BHA, BHT and other antioxidants. Crit Rev Toxicol 15: 109-115.

2. Canadanovic-Brunet JM, Djilas SM, Cetkovic GS, et al. (2005) Free-radical scavenging activity of wormwood (Artemisia absinthium L.) extracts. J Sci Food Agric 85: 265-272.

3. Djilas SM, Canadanovic-Brunet JM, Cetkovic GS, et al. (2003) Antioxidative activity of some herbs and species-review of ESR studies. In: Belton PS, Gill AM, Webb GA, Rutledge, D, Magnetic resonance in Food Science. (edn), RSC: Cambridge, UK.

4. Marimuthu P, Wu CL, Chang HT, et al. (2008) Antioxidant activity of the ethanolic extract from the bark of Chamaecyparis obtuse var. formosana. J Sci Food Agric 88: 1400-1405.

5. A Nostro, MP Germanò, VD'angelo, et al. (2000) Extraction methods and bioautography for evaluation of medicinal plant antimicrobial activity. Lett Appl Microbiol 30: 379-384.
6. Milic BLJ, Djilas SM, Canadanović-Brunet JM, et al. (2000) Polyphenols in plants. Faculty of Technology, University of Novi Sad, Novi Sad, 277-309.

7. Hakim RE (1969) Rediscovery of a treatment for vitiligo. Clio Medica 4: 277-289.

8. El Mofty AM (1948) A preliminary clinical report on the treatment of leucodermia with Ammi majus Linn. J Egypt Med Assoc 31: 651-665.

9. Abu Mustafa EA, Fayez MBE (1961) Natural coumarins I. Marmesin and marmesinin further products from the fruits of Ammi majus L. J Org Chem 26: 161-166.

10. Fahmy IR, Abu-Shady H (1982) The isolation and properties of ammoidin, ammidin and Ramadan, S. Ammi majus plant. Hamdard 25: 32-35.

11. El-Mofty AM (1952) Further study on treatment of leucodermia with Ammi majus Linn. J Egypt Med Assoc 35: 1-19.

12. Saima H, Jan A, Marwat KB, et al. (2014) Phytochemistry and medicinal properties of Ammi visnaga (Apiacae). Pak J Bot 46: 861-867.

13. Rehab MSH, Hossain MA (2016) Evaluation of antioxidant, antimicrobial and cytotoxic activities of seed crude extracts of Ammi majus grown in Oman. Egyptian Journal of Basic and Applied Sciences 3: 329-334.

14. Rehab MSH, Hossain MA (2016) Evaluation of antimicrobial and cytotoxic activities of polar solvents extracts of leaves of Ammi majus used by the Omanis. Pacific Science Review A: Natural Science and Engineering 18: 62-65.

15. Hussain I, Saleem S, Khan H, et al. (2015) Screening of Ammi Majus and Convolvulus Arvensis for antioxidant activities. MDSRC - 2015 Proceedings, Wah/Pakistan.

16. Abdul-Jalil TZ, Saour KY, Nasser AA (2010) Phytochemical study of some flavonoids present in the fruits of two Ammi L. species wildly grown in Iraq. Iraqi J Pharm Sci 19: 48-57.

17. Bencheraiet R, H Kherrab, A Kabouche, et al. (2011) Flavonols and antioxidant activity of Ammi visnaga L. (Apiaceae). Rec Nat Prod 5, 52-55.

18. Duarte J, Torres Al, Zarzuelo A (2000) Cardiovascular effects of visnagin on rats, Planta Med 66: 35-39.

19. Duarte J, Vizcaino FP, Torres Al, et al. (1995) Vasodilator effects of visnagin in isolated rat vascular smooth-muscle. Eur J Pharm 286: 115-122.

20. Eldomiaty MM (1992) Improve high-performance liquid-chromatographic determination of khellin and visnagin in Ammi visnaga fruits and pharmaceutical formulations. J Pharm Sci 81: 475-478.

21. Ghareeb AM, Zedan TH, Gharb LA (2011) Antibacterial and antifungal activities of Ammi visnaga extracts against pathogenic microorganisms. Iraqi J Sci 52: 30-36.

22. Rose J, Hulburd J (1992) The aromatherapy book applications and inhalations. North Atlantic Books, Berkeley, California, 94712.

23. Satrani B, Farah A, Fechtal M, et al. (2004) Chemical composition and antimicrobial and antifungal activities of the essential oil of Ammi visnaga (L.) Lam. Acta Bot Gal 151: 65-71.

24. Sonnenberg H, Kaloga M, Eisenbach N, et al. (1995) Isolation and characterization of an angular-type dihydropyranocoumaring- 
lycoside from the fruits of Ammi visnaga (L.) LAM. (Apiaceae). Zeitschrift fur Naturforschung C 50: 729-731.

25. Al-Snafi A (2015) Chemical constituents and pharmacological activities of Ammi majus and Ammi visnaga. A review. Inter J Pharm Ind Res 3: 257-265.

26. Khalfallah A, Labed A, Semra Z, et al. (2011) Antibacterial activity and chemical composition of the essential oil of Ammi visnaga L. (Apiaceae) from constantine, Algria. Int J Med Arom Plants 1 : 302-305.

27. Vanachayangkul P, Byer K, Khan S, et al. (2010) An aqueous extract of Ammi visnaga fruits and its constituents khellin and visnagin prevent cell damage caused by oxalate in renal epithelial cells. Phytomedicine 17: 653-658.

28. Zgorka G, Dragan T, Glowniak K, et al. (1998) Determination of furanochromones and pyranocoumarins in drugs and Amm visnaga fruits by combined solid-phase extraction-high-performance liquid chromatography and thin-layer chromatography-high performance liquid chromatography. J Chromatogr A 797: 305-309.

29. Muthukumran P, Begumand VH, Kalaiarasan P (2011) Anti-aiabetic activity of Ammi majus (L) leaf extracts. Inter J Pharm Tech Res 3: 136-139.

30. Mothana RA, Abdo SA, Hasson S, et al. (2010) Antimicrobial, antioxidant and cytotoxic activities and phytochemical screening of some Yemeni medicinal plants. Evid Based Complement Alternat Med 7: 323-330.

31. Akhtar MS, Ahmed M, Gulzar K, et al. (2011) Hypoglycemic activity of Ammi majus leaves in normal and alloxane-induced diabetic rabbits. Diabetologia Croatica 40: 71-79.

32. Jouad H, Maghrani M, Eddouks M (2002) Hypoglycemic effect of aqueous extract of Ammi visnagain normal and streptozotocin-induced diabetic rats. J Herb Pharmacother 2: 19-29.

33. Vanachayangkul P, Chow N, Khan SR, et al. (2011) Prevention of renal crystal deposition by an extract of Ammi visnaga $\mathrm{L}$. and its constituents khellin and visnagin in hyperoxaluric rats. Urol Res 39: 189-195.

34. Khaloud KA, Hossain MA (2016) New prenylated flavonoids from the leaves of Dodonea viscosa native to the Sultanate of Oman. Pac Sci Rev A: Nat Sci Eng 18: 53-61.

35. Lai PK, Roy J (2004) Antimicrobial and chemopreventive properties of herbs and spices. Curr Med Chem 11: 1451-1460.

36. Ammor K, Bousta D, Jennan S, et al. (2017) Total polyphenol content and antioxidant power of Ammi visnaga from Morocco. Der Pharma Chemica 9: 73-78.

37. Aourabi S, Driouch M, Sfaira M, et al. (2019) Influence of phenolic compounds on antioxidant and anticorrosion activities of Ammi visnaga extracts obtained ultrasonically in three solvent systems. Int J Electrochem Sci 14: 6376-6393. 